\title{
Surface effects in metallic iron nanoparticles
}

\author{
Bødker, Franz; Mørup, Steen; Linderoth, Søren
}

Published in:

Physical Review Letters

Link to article, DOI:

10.1103/PhysRevLett.72.282

Publication date:

1994

Document Version

Publisher's PDF, also known as Version of record

Link back to DTU Orbit

Citation (APA):

Bødker, F., Mørup, S., \& Linderoth, S. (1994). Surface effects in metallic iron nanoparticles. Physical Review Letters, 72(2), 282-285. https://doi.org/10.1103/PhysRevLett.72.282

\section{General rights}

Copyright and moral rights for the publications made accessible in the public portal are retained by the authors and/or other copyright owners and it is a condition of accessing publications that users recognise and abide by the legal requirements associated with these rights.

- Users may download and print one copy of any publication from the public portal for the purpose of private study or research.

- You may not further distribute the material or use it for any profit-making activity or commercial gain

- You may freely distribute the URL identifying the publication in the public portal

If you believe that this document breaches copyright please contact us providing details, and we will remove access to the work immediately and investigate your claim. 


\title{
Surface Effects in Metallic Iron Nanoparticles
}

\author{
F. Bødker, ${ }^{*}$ S. Mørup, and S. Linderoth ${ }^{\dagger}$ \\ Physics Department, Technical University of Denmark, DK-2800 Lyngby. Denmark
}

(Received 26 October 1993)

\begin{abstract}
Nanoparticles of metallic iron on carbon supports have been studied in situ by use of Mössbauer spectroscopy. The magnetic anisotropy energy constant increases with decreasing particle size, presumably because of the influence of surface anisotropy. Chemisorption of oxygen results in formation of a surface layer with magnetic hyperfine fields similar to those of thicker passivation layers, and with a ferromagnetic coupling to the spins in the core of the particles. In contrast, thicker passivation layers have a noncollinear spin structure.

PACS numbers: $75.60 . J p, 75.30 . \mathrm{Gw}, 76.80 .+\mathrm{y}$
\end{abstract}

Nanosized magnetic particles have properties that are significantly different from those of the corresponding bulk materials. They are single-domain particles and the magnetization direction fluctuates spontaneously (superparamagnetic relaxation) with a relaxation time given by [1]

$$
\tau=\tau_{0} \exp \left(\Delta E_{a} / k T\right),
$$

where $T$ is the temperature and $k$ is Boltzmann's constant. $\tau_{0}$ is of the order of $10^{-10}-10^{-13} \mathrm{~s}$ and $\Delta E_{a}$ is the anisotropy energy barrier, which can be expressed as the product of an effective anisotropy energy constant $K_{\text {eff }}$ and the volume $V$.

A large fraction of the atoms in nanoparticles are surface atoms; this has a significant influence on the magnetic properties. Studies of thin films have, for example, shown that the magnetic hyperfine fields of surface atoms can differ considerably from the bulk value $[2,3]$. Nanoparticles of transition metals have a great affinity to oxygen and studies of such particles must therefore be performed in situ in a reducing atmosphere, in ultrahigh vacuum or in an inert atmosphere. The intrinsic magnetization and the magnetic hyperfine fields in the core and at the surface may depend on both the particle size and the temperature. Such effects are difficult to measure unless the superparamagnetic relaxation is slow [4]. Therefore, in order to study the magnetic properties in detail it is necessary to perform measurements both at low and high temperatures in large applied magnetic fields.

Here we report on Mössbauer studies of $\alpha$-Fe particles with average diameters down to $2 \mathrm{~nm}$. The measurements were carried out with the samples kept in an in situ cell consisting of a small glass cylinder with very thin windows, which allow transmission of gamma radiation. Two tubes connect the cell to a gas handling system via a pair of glass-to-metal seals. This allows a flow of different high purity gases to pass through the cell, to evacuate it to high vacuum, or to seal it off. The setup is sufficiently flexible that the cell can be placed in an oven for reduction in hydrogen at a high temperature and it can be placed in a liquid helium cryostat with a superconducting magnet in which Mössbauer measurements can be made at temperatures between 5 and $300 \mathrm{~K}$ and with applied magnetic fields up to $4.3 \mathrm{~T}$.

Metallic iron particles were prepared on carbon black supports (Monarch 1300, $560 \mathrm{~m}^{2} \mathrm{~g}^{-1}$ and Black Pearl 2000, $1475 \mathrm{~m}^{2} \mathrm{~g}^{-1}$, both from Cabot Corp.). The activated carbon supports were impregnated with aqueous solutions of ferric nitrate enriched with ${ }^{57} \mathrm{Fe}$ and dried carefully in ambient air at temperatures up to $400 \mathrm{~K}$ as described elsewhere $[4,5]$. The sample was then placed in the in situ cell and reduced in a flow of high purity hydrogen $(99.9995 \%)$ at temperatures of the order of 600 $\mathrm{K}$. We prepared a number of samples. The average particle size was varied by changing the iron concentration and the reduction temperature.

The particle size was determined from the magnetic field dependence of the Mössbauer spectra above the superparamagnetic blocking temperature $T_{B}$, defined as the temperature at which the magnetic hyperfine splitting in zero field spectra has collapsed because of fast superparamagnetic relaxation. Above $T_{B}$ the magnetic field at the nucleus, observed when a magnetic field $B$ is applied. is for $\mu B / k T \gtrsim 2$ given by $[6,7]$

$$
B_{\mathrm{obs}}=B_{0}(1-k T / \mu B)-B \text {. }
$$

Here $B_{0}$ is the saturation magnetic hyperfine field and $\mu$ is the magnetic moment of a particle. A plot of $B_{\text {obs }}+B$ as a function of $B^{-1}$ thus gives a straight line. From the slope and intercept the values of $\mu$ and $B_{0}$ can be determined. Even for relatively large values of the magnetic anisotropy this procedure can be used to obtain reliable values of $\mu$ [7]. If one assumes that the saturation magnetization $M_{s}$ of the particles is known the particle volume, $V=\mu / M_{s}$, can be calculated.

Figure 1 shows Mössbauer spectra of a sample with an average particle diameter of $2.4 \pm 0.3 \mathrm{~nm}$. At $5 \mathrm{~K}$ the main component has Mössbauer parameters similar to those of bulk $\alpha-\mathrm{Fe}$. The spectrum also contains a component due to an amorphous iron-carbide phase with a magnetic hyperfine field of about $25 \mathrm{~T}$ and a component with magnetic hyperfine fields of 36-40 T, which can be attributed to surface atoms. The two latter components are better resolved in spectra obtained in large applied fields [4,5]. Even in a sample with $2 \mathrm{~nm}$ Fe particles, which contain only about 350 atoms, a large fraction of 


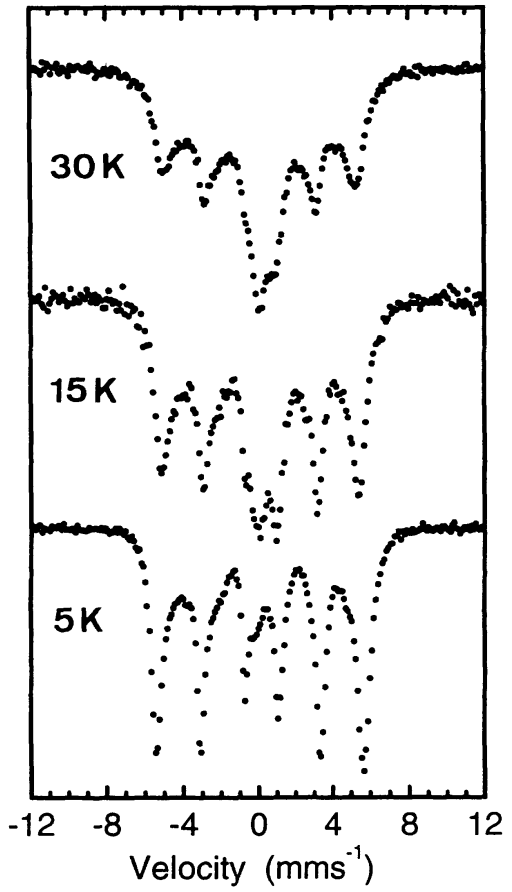

FIG. 1. Mössbauer spectra of $2.4 \mathrm{~nm}$ iron particles at the indicated temperatures.

the atoms were found to be in environments similar to those in bulk $\alpha-\mathrm{Fe}$ [8].

The spectra obtained at 15 and $30 \mathrm{~K}$ (Fig. 1) show a gradual broadening of the lines with increasing temperature and an enhanced absorption near zero velocity. This shows that the superparamagnetic relaxation time is shorter than about $10^{-8} \mathrm{~s}$ even below $30 \mathrm{~K}$. The magnetic hyperfine field of the $\alpha-\mathrm{Fe}$ component below $15 \mathrm{~K}$ is slightly smaller than that of larger single-domain particles. This is because of the influence of collective magnetic excitations [9] (fast fluctuations of the magnetization direction around an easy direction of magnetization) which results in a reduction of the observed magnetic hyperfine field given by $[9,10]$

$$
B_{\text {obs }}=B_{0}\left(1-k T / 2 K_{\text {eff }}^{\prime} V\right) \text {, }
$$

where $K_{\text {eff }}^{\prime}$ is related to the anisotropy field. Values of $K_{\text {eff }}^{\prime}$ were determined from measurements below $T_{B}$ for $\alpha$-Fe particles with different sizes using Eq. (3). It was

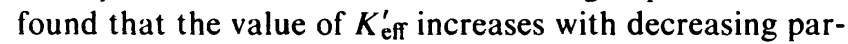
ticle size. Earlier studies of metallic particles have shown that the value of $K_{\text {eff }}^{\prime}$ changes when different molecules are chemisorbed on the particles $[11,12]$. This shows that surface anisotropy gives an important contribution to $K_{\text {eff. }}^{\prime}$ We have analyzed the results on the basis of a simple model in which the total energy barrier is written as

$$
\Delta E_{a}=K_{\mathrm{eff}}^{\prime} V=K_{l}^{\prime} V+K_{s}^{\prime} S,
$$

where $K_{v}^{\prime}$ and $K_{s}^{\prime}$ are the volume and the surface anisotropy energy constants, respectively, and $S$ is the surface

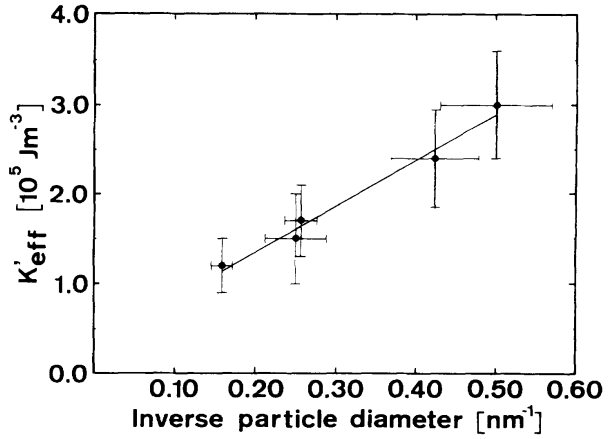

FIG. 2. Magnetic anisotropy energy constant of $\alpha$-Fe particles as a function of the reciprocal particle diameter.

area. Assuming that the particles are spherical with diameter $d$, Eq. (4) can be written as

$$
K_{\text {eff }}^{\prime}=K_{t}^{\prime}+\frac{6}{d} K_{s}^{\prime} .
$$

Figure 2 shows a plot of $K_{\text {eff }}^{\prime}$ as a function of $d^{-1}$. The size dependence of $K_{\text {eff }}^{\prime}$ is in accordance with Eq. (5) and the straight-line fit yielded the values $K_{r}^{\prime}=(0.3 \pm 0.3)$ $\times 10^{5} \mathrm{~J} \mathrm{~m}^{-3}$ and $K_{s}^{\prime}=(0.09 \pm 0.03) \times 10^{-3} \mathrm{~J} \mathrm{~m}^{-2}$. The estimated value of $K_{r}^{\prime}$ is close to the value of the cubic anisotropy energy constant $K_{1}$ for $\alpha-\mathrm{Fe}\left(\approx 0.5 \times 10^{5}\right.$ $\mathrm{J} \mathrm{m}^{-3}$ ), as expected if magnetocrystalline anisotropy is predominant [10]. However, this result does not give evidence for the absence of other contributions to the anisotropy. It is likely that both shape anisotropy and stress anisotropy contribute to the total anisotropy, but the different contributions may partly oppose each other.

Studies of thin $\alpha$-Fe films have shown that $K_{s}$ $\approx 1.0 \times 10^{3} \mathrm{~J} \mathrm{~m}^{-2}$, and that the surface anisotropy is perpendicular to the surface [13]. The value of $K_{s}$ found for the iron particles is much smaller. However, if the particles are assumed to have perfect spherical shape, symmetry arguments show that the total contribution to $\Delta E_{a}$ from surface anisotropy is zero. The net contribution to $K_{\text {eff }}$ from surface effects in small particles is a result of deviations from spherical symmetry and can therefore be expected to be much smaller than the value found in thin film studies.

The influence of chemisorption of oxygen was studied in a sample with an average particle diameter of $4.0 \mathrm{~nm}$. The hydrogen was first removed by heating at $550 \mathrm{~K}$ for $2 \mathrm{~h}$ while the in situ cell was evacuated. Mössbauer spectra at $5 \mathrm{~K}$ of samples in $\mathrm{H}_{2}$ and in vacuum were found to be essentially identical. The sample was then exposed to a flow $\left(7 \mathrm{~cm}^{3} \mathrm{~min}^{-1}\right)$ of argon containing $80 \mathrm{ppm}$ oxygen at room temperature. If all oxygen reacted with the $\alpha-\mathrm{Fe}$ particles this would correspond to one oxygen atom per surface iron atom after approximately $3 \mathrm{~h}$ flow. Measurements were made after exposure for 2,6 , and $26 \mathrm{~h}$. A new component with a magnetic hyperfine field larger than $40 \mathrm{~T}$ was found to appear. After $2 \mathrm{~h}$ the relative area of this new component was about $10 \%$ and after $6 \mathrm{~h}$ 


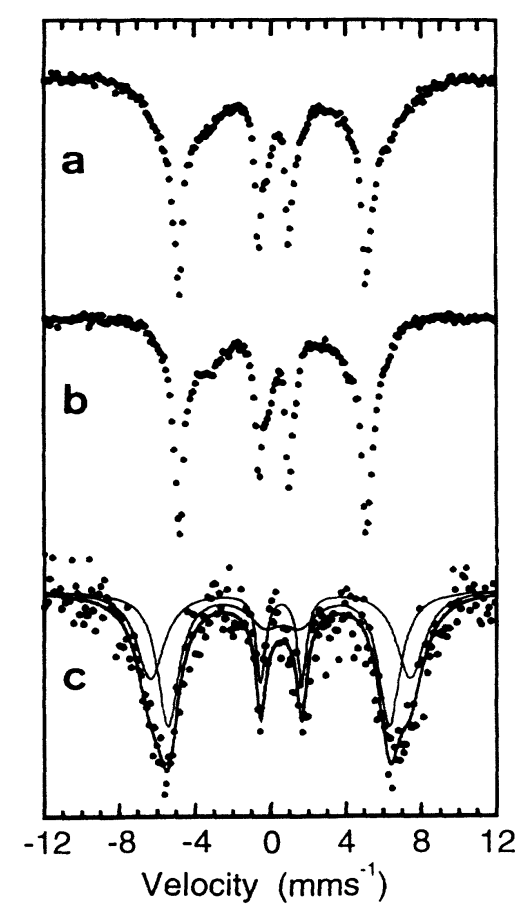

FIG. 3. Mössbauer spectra of $4 \mathrm{~nm}$ iron particles. (a) After exposure to the gas flow for $6 \mathrm{~h}$; (b) before exposure to the gas flow; (c) the difference between spectra (a) and (b) after multiplying (b) with a scaling factor (see text).

it was about $20 \%$. (If the particles are spherical about $25 \%$ of the iron atoms are in the surface layer.) The parameters of the components were essentially identical after 2 and $6 \mathrm{~h}$.

Figure 3 shows the Mössbauer spectra of the nonexposed sample and the sample exposed to oxygen for $6 \mathrm{~h}$ in a magnetic field of $4.3 \mathrm{~T}$ applied parallel to the $\gamma$-ray direction. Both spectra indicate the absence of absorption lines corresponding to the $\Delta m=0$ transitions; i.e., all phases seem to have either a ferromagnetic or a ferrimagnetic structure. The oxygen exposure is seen to give rise to a magnetically split component with very broad lines and with an average hyperfine field which is larger than that of $\alpha$-iron. In order to study this component in more detail we have subtracted the spectrum of the nonexposed sample [Fig. 3(b)] from that of the oxygen-exposed sample [Fig. 3(a)]. A scaling factor was used such that the $\alpha$-iron component disappeared completely from the difference spectrum [Fig. 3(c)]. Two sextets could fit the difference spectrum well [the solid lines in Fig. 3(c)]. Within the uncertainties lines 2 and 5 of the both sextets had zero intensities. The fitting parameters are given in Table I together with the corresponding hyperfine parameters of the difference spectrum for the samples measured in zero applied field. From Table I it can be seen that for both magnetically split components the total magnetic field at the nucleus is almost exactly $4.3 \mathrm{~T}$ smaller when a field of $4.3 \mathrm{~T}$ is applied parallel to the $\gamma$ direction than when no field is applied. This shows that the surface layer is ferromagnetically ordered. This magnetic structure is different from those of known bulk ferric-oxide phases, which are ordered ferrimagnetically $\left(\mathrm{Fe}_{3} \mathrm{O}_{4}\right.$ and $\gamma$ $\left.\mathrm{Fe}_{2} \mathrm{O}_{3}\right)$ or antiferromagnetically $\left(\alpha-\mathrm{Fe}_{2} \mathrm{O}_{3}\right)$. Furthermore, these known oxide phases have magnetic hyperfine fields of the order of 50-55 $\mathrm{T}$ at $5 \mathrm{~K}$, quite different from the magnetic hyperfine fields of the iron nuclei in the oxidized surface layer (see Table I). There was no indication of the presence of $\mathrm{FeO}$ in any of the spectra.

Studies of an oxidized Fe(001) surface by use of spinpolarized photoemission $[14,15]$ also indicated that initial chemisorption of oxygen did not affect the magnetic ordering at the surface; i.e., the oxidized surface atoms were ferromagnetically coupled to the substrate. This is in agreement with our observations.

After the exposure to the gas flow for $26 \mathrm{~h}$ all the iron was oxidized. Figure 4 shows Mössbauer spectra obtained at $5 \mathrm{~K}$ in zero applied magnetic field and in a 4.3 $\mathrm{T}$ field applied parallel to the gamma ray direction. In the $4.3 \mathrm{~T}$ spectrum lines 2 and 5 have the same relative intensity as in the zero-field spectrum. The only effect of the applied field is a broadening of the lines. The widths of lines 1 and 6 increase by about $0.35 \mathrm{mms}^{-1}$. Al-

TABLE I. Mössbauer parameters of the oxide components for $4 \mathrm{~nm}$ iron particles. Isomer shifts are given relative to $\alpha-\mathrm{Fe}$ at $295 \mathrm{~K}$. The uncertainties in the isomer shifts and quadrupole shifts are $\pm 0.1 \mathrm{~mm} \mathrm{~s}^{-1}$, for the magnetic field the uncertainty is $\pm 0.5 \mathrm{~T}$, and for the relative areas $\pm 5 \%$.

\begin{tabular}{lccccc}
\hline \hline & $\begin{array}{c}\text { Quadrupole } \\
\text { Isomer shift } \\
\left(\mathrm{mm} \mathrm{s}^{-1}\right)\end{array}$ & $\begin{array}{c}\text { Mhift } \\
\left(\mathrm{mm} \mathrm{s}^{-1}\right)\end{array}$ & $\begin{array}{c}\text { Magnetic field } \\
(\mathrm{T})\end{array}$ & $\begin{array}{c}\text { Relative area } \\
(\%)\end{array}$ \\
\hline $\begin{array}{c}\text { Surface } \\
\text { layer }\end{array}$ & $B=4.3 \mathrm{~T}$ & 0.56 & -0.01 & 42.8 & 46 \\
& & 0.54 & -0.06 & 36.5 & 54 \\
Fully & $B=0$ & 0.44 & -0.04 & 47.2 & 44 \\
oxidized & $B=4.3 \mathrm{~T}$ & 0.43 & -0.01 & 41.2 & 56 \\
& & 0.51 & -0.01 & 46.9 & 58 \\
& $B=0$ & 0.48 & -0.03 & 41.4 & 42 \\
\hline \hline
\end{tabular}




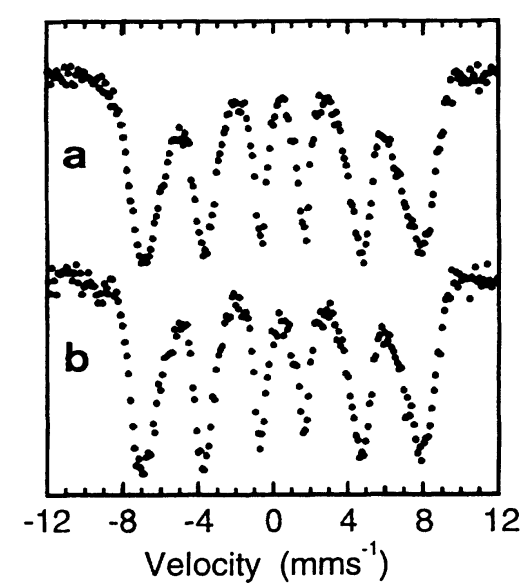

FIG. 4. Mössbauer spectra of $4 \mathrm{~nm}$ iron particles after exposure to the gas flow for $26 \mathrm{~h}$. The spectra were obtained at $5 \mathrm{~K}$ in a magnetic field of $4.3 \mathrm{~T} \mathrm{(a)}$ and in zero applied field (b).

though electron diffraction studies of similar surface oxide phases on metallic iron particles have shown that a spinel phase $\left(\gamma-\mathrm{Fe}_{2} \mathrm{O}_{3}\right.$ or $\left.\mathrm{Fe}_{3} \mathrm{O}_{4}\right)$ [16-18] is formed, the small size of the crystallites results in a noncollinear magnetic structure, presumably because of extensive spincanting effects $[19,20]$. The Mössbauer parameters of the fully oxidized particles, obtained from a fit with two sextets, are given in Table I. It is interesting that the magnetic hyperfine fields are nearly identical to those of the oxidized surface layer in zero applied field. The magnetic hyperfine fields of thick passivation layers of bigger iron particles are slightly larger $(\approx 50 \mathrm{~T})$, but the value decreases with decreasing thickness of the layer [1618,21-23].

The main conclusions of the present work can be summarized as follows: (1) Metallic iron particles with diameters down to about $2 \mathrm{~nm}$ have properties similar to bulk $\alpha$-Fe. (2) The magnetic anisotropy energy constant increases with decreasing particle size, presumably because of the influence of surface effects. (3) Chemisorption of oxygen results in formation of a surface layer, which is ferromagnetically coupled to the core of the particles, but with magnetic hyperfine fields similar to those found in thicker passivation layers, which have a disordered spin structure.

The work was supported by the Danish Council for Technical Research and by the EEC Commission.
*On leave from University College of North Wales, Bangor, United Kingdom.

†Present address: Materials Department, Ris $\emptyset$ National Laboratory, DK-4000 Roskilde, Denmark.

[1] L. Néel, Ann. Geophys. 5, 99 (1949).

[2] T. Shinjo, Surf. Sci. Rev. 12, 51 (1991), and references therein.

[3] A. J. Freeman and R. Wu, J. Magn. Magn. Mater. 104-107, 1 (1992), and references therein.

[4] F. Bødker, S. Mørup, and J. W. Niemantsverdriet, Catal. Lett. 13, 195 (1992).

[5] F. Bødker, S. Mørup, C. A. Oxborrow, S. Linderoth, M. B. Madsen, and J. W. Niemantsverdriet, J. Phys. Condens. Matter 4, 6555 (1992).

[6] S. Mørup, J. A. Dumesic, and H. Topsøe, in Applications of Mössbauer Spectroscopy, edited by R. L. Cohen (Academic, New York, 1980), Vol. II, p. 1.

[7] S. Mørup, P. H. Christensen, and B. S. Clausen, J. Magn. Magn. Mater. 68, 160 (1987).

[8] F. Bødker and S. Mørup, Hyperfine Interact. (to be published).

[9] S. Mørup and H. Topsøe, Appl. Phys. 11, 63 (1976).

[10] S. Mørup, J. Magn. Magn. Mater. 37, 39 (1983).

[11] B. S. Clausen, S. Mørup, and H. Topsøe, Surf. Sci. 82, L589 (1979).

[12] S. Mørup, H. Topsøe, and B. S. Clausen, Phys. Scr. 25, 713 (1982).

[13] K. B. Urquhart, B. Heinrich, J. F. Cochran, A. S. Arrott, and K. Myrtle, J. Appl. Phys. 64, 5334 (1988).

[14] P. D. Johnson, A. Clarke, N. B. Brookes, S. L. Hulbert, B. Sinkovic, and N. V. Smith, Phys. Rev. Lett. 61, 2257 (1988).

[15] B. Sinkovic, P. D. Johnson, N. B. Brookes, A. Clarke, and N. B. Smith, Phys. Rev. Lett. 65, 1647 (1990).

[16] S. Linderoth, M. D. Bentzon, and S. Moørup, Nucl. Instrum. Methods Phys. Res., Sect. B 76, 173 (1993).

[17] K. Haneda and A. H. Morrish, Surf. Sci. 77, 584 (1978).

[18] S. Gangopadhyay, G. C. Hadjipanayis, S. I. Shah, C. M. Sorensen, K. J. Klabunde, V. Papaefthymiou, and A. Kostikas, J. Appl. Phys. 70, 5888 (1991).

[19] J. M. D. Coey, Phys. Rev. Lett. 27, 1140 (1971).

[20] A. H. Morrish and K. Haneda, J. Magn. Magn. Mater. 35, 105 (1983).

[21] Y. Maeda, M. Aramaki, Y. Takashimi, M. Oogai, and T. Goto, Bull. Chem. Soc. Jpn. 60, 3241 (1987).

[22] I. Tamura and M. Hayashi, Surf. Sci. 146, 501 (1984).

[23] S. Gangopadhyay, G. C. Hadjipanayis, B. Dale, C. M. Sorensen, K. J. Klabunde, V. Papaefthymiou, and A. Kostikas, Phys. Rev. B 45, 9778 (1992). 